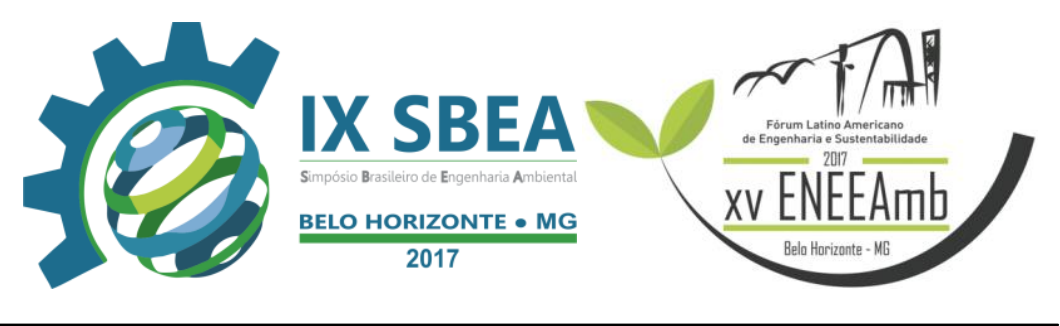

ÁREAS DEGRADADAS E CONTAMINADAS

\title{
AVALIAÇÃO DO DESENVOLVIMENTO DA ESPÉCIE EUCALYPTUS GRANDIS EM SOLO CONTAMINADO POR ÓLEO DE COZINHA
}

André Luiz Ramos - andreluizengamb@ gmail.com

Centro Universitário de Patos de Minas - UNIPAM

Débora Clarisa Teles - deborateles.engamb@gmail.com

Centro Universitário de Patos de Minas - UNIPAM

Laís Ferreira Caixeta - lais.caixeta@outlook.com

Centro Universitário de Patos de Minas - UNIPAM

Larissa Cristina Ribeiro Porto - larissa.porto.engamb@ gmail.com

Centro Universitário de Patos de Minas - UNIPAM

Sthéferson Bruno da Silva - sthefersonbrunoam@gmail.com

Centro Universitário de Patos de Minas - UNIPAM

Tiago Santos e Souza - tiagoss@ unipam.edu.br 


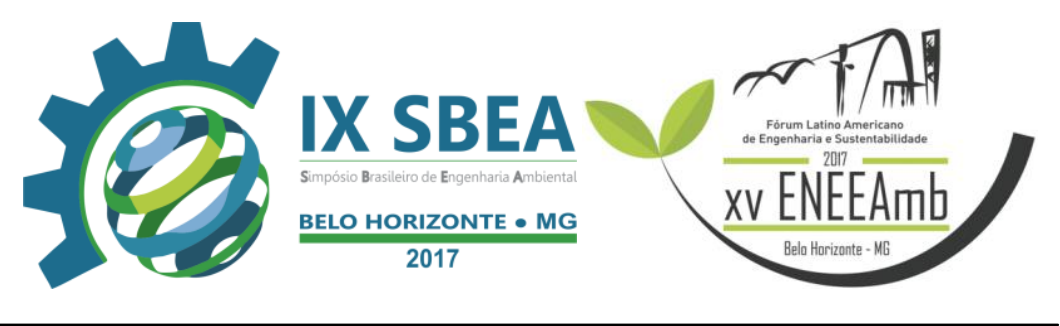

\section{RESUMO}

O óleo vegetal é um produto amplamente utilizado pela população e erroneamente descartado no meio ambiente. O objetivo deste estudo foi avaliar o desenvolvimento de 20 mudas da espécie Eucalyptus grandis em solo contaminado por óleo de cozinha, previamente utilizado para fins alimentícios. $\mathrm{O}$ experimento foi realizado na estufa 1 do Centro Universitário de Patos de Minas localizado na cidade de Patos de Minas (MG), as mudas foram transplantadas para vasos previamente preenchidos com área lavada e posteriormente contaminados com diferentes proporções do contaminante $(0 \mathrm{ml}, 10 \mathrm{ml}, 20 \mathrm{ml}, 30 \mathrm{ml}$ e $40 \mathrm{ml})$, divididos em cinco tratamentos (T1,T2,T3,T4 E T5). Adotaram-se procedimentos empíricos para coleta periódica de dados das plantas ao longo de 32 dias. Após esse período foi feita a análise morfológica e a averiguação da parte radicular de cada tratamento, correlacionando os resultados com cada tratamento. A espécie estudada apresenta tolerância ao óleo de cozinha na concentração de até $2,5 \mathrm{~mL} / \mathrm{kg}$ de solo. Doses acima desse valor causam senescência na planta. Os tratamentos $\mathrm{T} 1, \mathrm{~T} 2, \mathrm{~T} 3$ e $\mathrm{T} 4$ se mostraram relativamente tolerantes ao contaminante apesar de apresentarem folhas arroxeadas o que indica falta de nutrientes. Estudos complementares nessa espécie são interessantes a fim de se aprofundar o conhecimento.

Palavras-chave: contaminação, eucalipto, dosagem.

\section{INTRODUÇÃO E OBJETIVO}

Nos últimos anos a preocupação com substâncias contaminantes lançadas no meio ambiente aumentou, sobretudo no solo, devido ao aumento nas emissões desses poluentes, em consequência das atividades antrópicas (IVES \&CARDINALE,2004; GIACHETTI \& SEBASTIANI, 2006). 


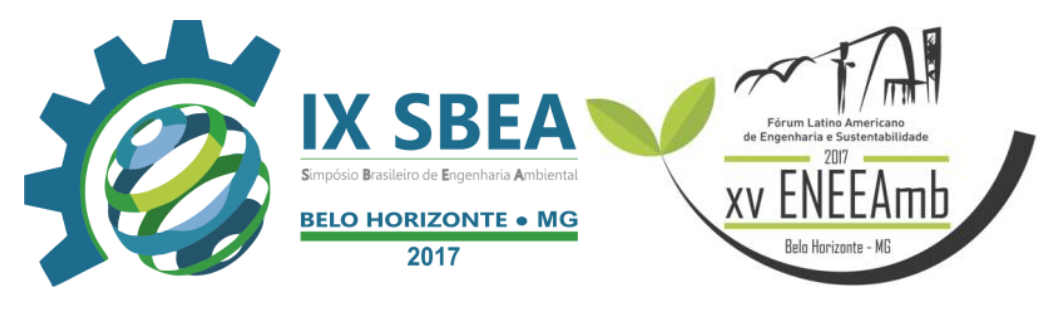

O óleo de cozinha é um clássico exemplo de contaminante de origem humana e raramente esse produto é eliminado de maneira adequada, sendo descartado através dos ralos de pias ou em lotes vagos.

Como todo material de origem orgânica, a decomposição do óleo é responsável pela emissão de metano na atmosfera contribuindo para o superaquecimento terrestre. Fica evidente a importância dos cidadãos evitarem o descarte do óleo no lixo comum. Hoje ainda não há uma opção de descarte de forma ideal para o óleo já usado. Seja junto ao lixo orgânicas, seja despejado no ralo, privadas ou pias, o custo sempre é alto para o meio ambiente (NETO, 2010).

O óleo pode ficar retido nos encanamentos, atraindo pragas, ou pode seguir caminho e ser tratado e separado da água nas estações de tratamento de esgoto das cidades. A situação fica complicada, pois no Brasil nenhuma cidade tem a coleta de esgoto totalmente eficiente. O óleo que chega aos corpos hídricos das cidades estagna na superfície da água e pode impedir a entrada da luz que alimentaria os fitos plânctons, organismos essenciais para a cadeia alimentar aquática. Além disso, quando atinge o solo, o óleo tem a capacidade de impermeabilizá-lo, tornando difícil o escoamento de água das chuvas, por exemplo. Essa situação é propícia para as enchentes (NETO, 2010).

SOARES et al (2005) em pesquisa demonstrou que as espécies Eucalyptus maculata e Eucalyptus urophylla apresentam certa tolerância a níveis de cádmio. Para aprofundar o conhecimento sobre o gênero Eucalyptus à resistência de contaminantes foi escolhida para verificação a espécie Eucalyptus grandis. O Eucalyptus grandisnatural da Austrália, principalmente dos estados de New South Wales (NSW) e Queensland (QLD),apresenta estágios acelerados de crescimento, possui sistema radicular desenvolvido e fácil adaptação a condições de estresse (DELL e DAPING, 1995), e por isso dá uma resposta rápida aos possíveis efeitos causados pelo contaminante.

Entende-se que é de grande importância analisar os efeitos do óleo no solo e o desenvolvimento da vegetação nessas áreas contaminadas, uma vez que, esse produto é amplamente utilizado pela população e erroneamente descartado. Dessa forma, futuros 


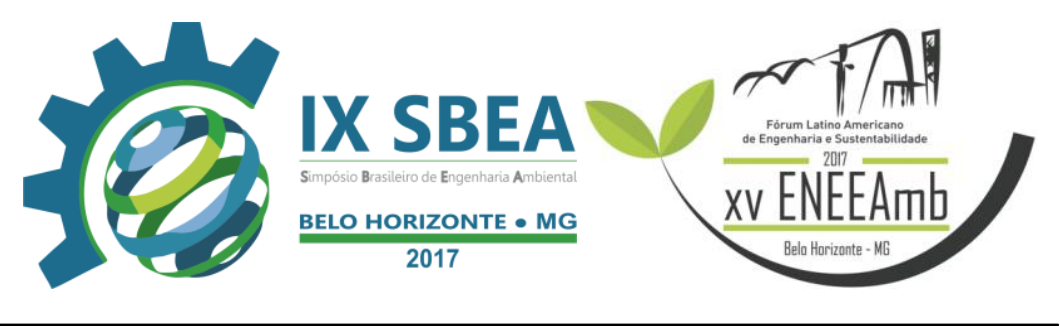

danos podem ser prevenidos garantindo a proteção ambiental e a manutenção da qualidade de vida da sociedade.

Diante de tal conjuntura, o presente estudo visa avaliar o desenvolvimento do eucalipto em solo contaminado por doses de óleo de cozinha, previamente utilizado para fins alimentícios.

\section{MATERIAL E MÉTODOS}

O projeto foi realizado na estufa 1 do Centro Universitário de Patos de Minas localizado na cidade de Patos de Minas (MG), nas coordenadas Latitude $18^{\circ} 34^{\prime} 22,02^{\prime \prime}$ S e Longitude 46 $30^{\prime} 47,49^{\prime \prime}$ W. As mudas para análise foram cedidas pelo Instituto Estadual de Florestas (IEF). Foram selecionadas 20 mudas, aleatórias, de tamanho uniforme da espécie em questão para serem transplantadas em vasos plásticos devidamente etiquetados, identificando os tratamentos e repetições e preenchidos parcialmente com $12 \mathrm{~kg}$ de areia lavada.

Adotou-se, para o plantio, o método de blocos ao acaso, o qual consiste em pequenos agrupamentos (blocos) com parcelas aproximadamente semelhantes, sendo que foi aplicado um sistema de rotação periódica dos mesmos, visando à distribuição igualitária de luz solar. Estabeleceu-se o período de 7 dias para a adaptação das plantas ao clima da estufa que, devido à época do ano, encontrava-se com altos índices de incidência de luz solar e elevada temperatura.

Ao decorrer do período de estudo, irrigaram-se os cultivares de forma regular, seis vezes por semana, com $300 \mathrm{ml}$ de água, e a cada sete dias administrava-se uma solução contendo micronutrientes essenciais para o desenvolvimento das mudas, conhecida como "sopa nutritiva" proposta por Mead Johnson.

Adotaram-se procedimentos empíricos para coleta de dados das plantas em períodos de sete em sete dias, que consistiam na aferição da altura das plantas com uma trena de 30 centímetros, contagem das folhas emitidas e senescentes, aparecimento de folhas amareladas e arroxeadas denunciando algum tipo de deficiência, bem como a morte das mudas. 


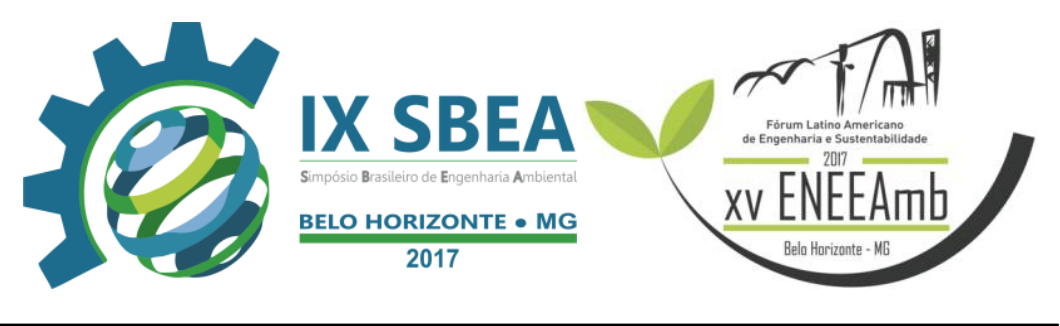

A aplicação do contaminante, o óleo de cozinha, foi realizada uma semana após a primeira dosagem da solução nutritiva. Para a administração do mesmo, foi utilizado um béquer graduado em $100 \mathrm{ml}$ e uma proveta graduada em $50 \mathrm{ml}$ para fazer a medição da dosagem. O contaminante foi diretamente ministrado junto à quantia de sua irrigação diária. As ações de aplicação foram separadas por tratamentos (T1, T2, T3, T4 e T5) e em repetições (R1, R2, R3 e R4) sendo que o primeiro tratamento (T1) foi poupado do contaminante e os demais receberam suas dosagens especificas. A tabela a seguir mostra a relação dos tratamentos e as quantidades de contaminantes para cada repetição.

Tabela 1- Quantidade de contaminante por tratamento.

\begin{tabular}{cccccc}
\hline \multicolumn{5}{c}{ Tratamento (T) e Repetições (R) } \\
\hline & T1 & T2 & T3 & T4 & T5 \\
R1 & $0 \mathrm{ml}$ & $10 \mathrm{ml}$ & $20 \mathrm{ml}$ & $30 \mathrm{ml}$ & $40 \mathrm{ml}$ \\
$\mathrm{R} 2$ & $0 \mathrm{ml}$ & $10 \mathrm{ml}$ & $20 \mathrm{ml}$ & $30 \mathrm{ml}$ & $40 \mathrm{ml}$ \\
$\mathrm{R} 3$ & $0 \mathrm{ml}$ & $10 \mathrm{ml}$ & $20 \mathrm{ml}$ & $30 \mathrm{ml}$ & $40 \mathrm{ml}$ \\
$\mathrm{R} 4$ & $0 \mathrm{ml}$ & $10 \mathrm{ml}$ & $20 \mathrm{ml}$ & $30 \mathrm{ml}$ & $40 \mathrm{ml}$ \\
\hline
\end{tabular}

Fonte: Acervo dos autores.

Todo o experimento durou cerca de 32 dias desde o plantio das mudas até sua retirada dos vasos para averiguações.

\section{RESULTADOS E DISCUSSÃO}

As plantas médias de cada tratamento foram retiradas e fotografadas para comparações de morfologia e características de cada tratamento. Após esse processo todas as plantas foram retiradas dos vasos para averiguação da parte radicular e os efeitos de cada dose de contaminante sobre elas. Não foram encontrados efeitos visíveis sobre as raízes.

As mudas foram levadas para laboratório para ser feita a pesagem das folhas, das raízes e o caule, e posteriormente correlacionadas com as doses do contaminante aplicadas. Os resultados coletados apresentam-se nos gráficos a seguir: 


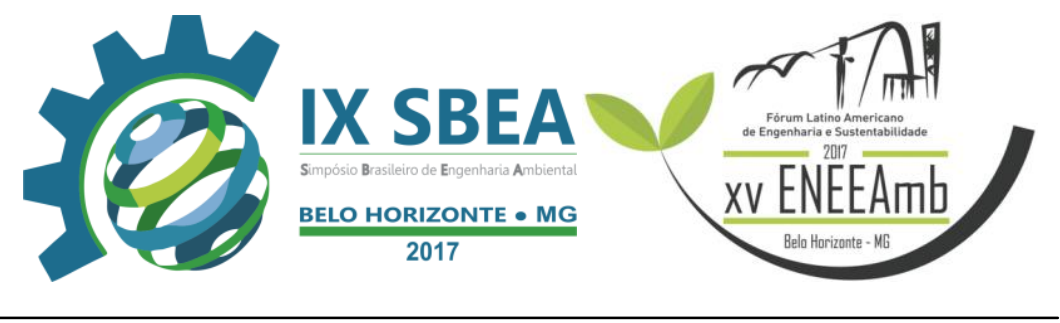

Figura 1-Relação de doses do contaminante e o número de folhas nas plantas

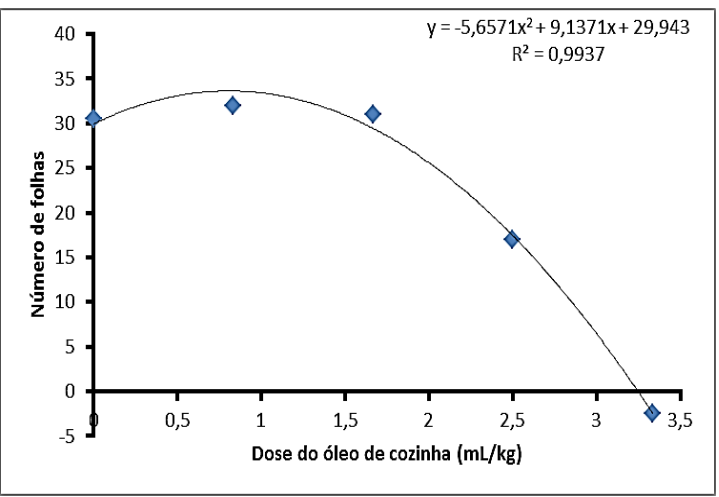

Fonte: Acervo dos autores.

Figura 2- Relação de doses do contaminante e a altura dos caules das plantas

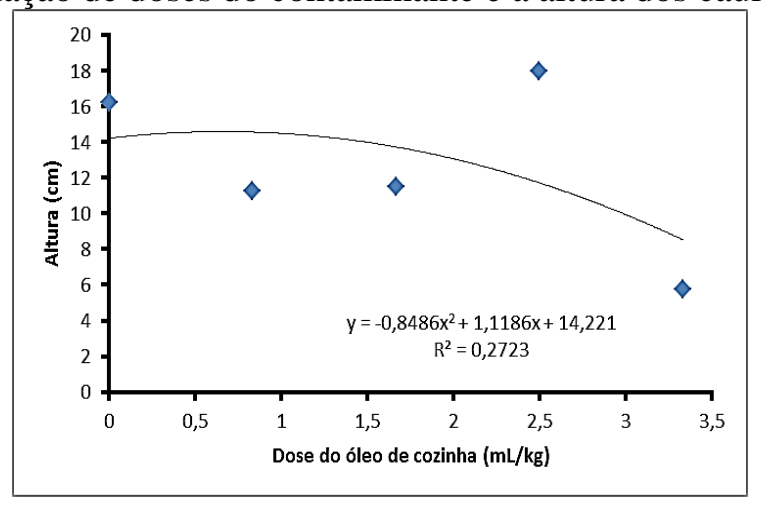

Fonte: Acervo dos autores.

Figura 3- Relação de doses do contaminante e o número de ramificações das plantas

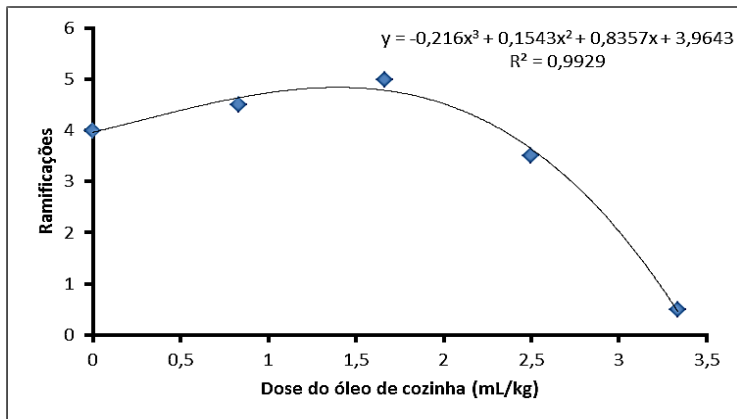

Fonte: Acervo dos autores. 


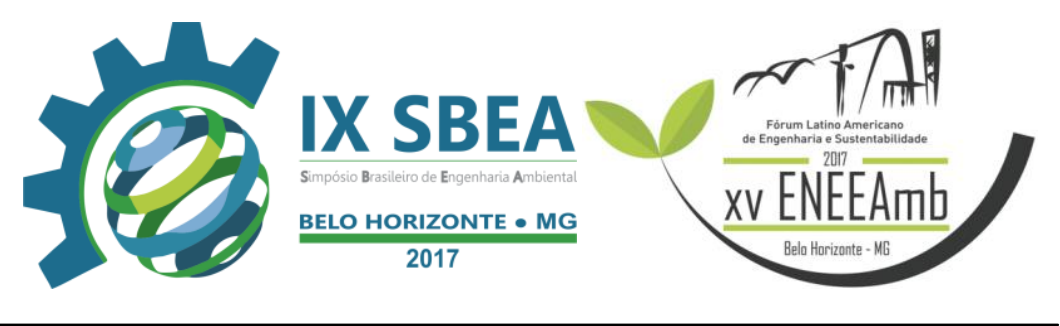

Figura 4- Relação das doses de contaminante e a massa em gramas das folhas das plantas

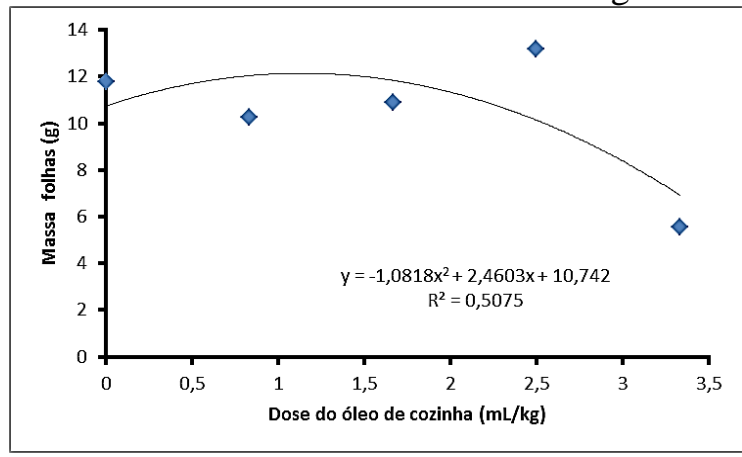

Fonte: Acervo dos autores.

Figura 5- Relação das doses do contaminante com a massa das raízes da planta

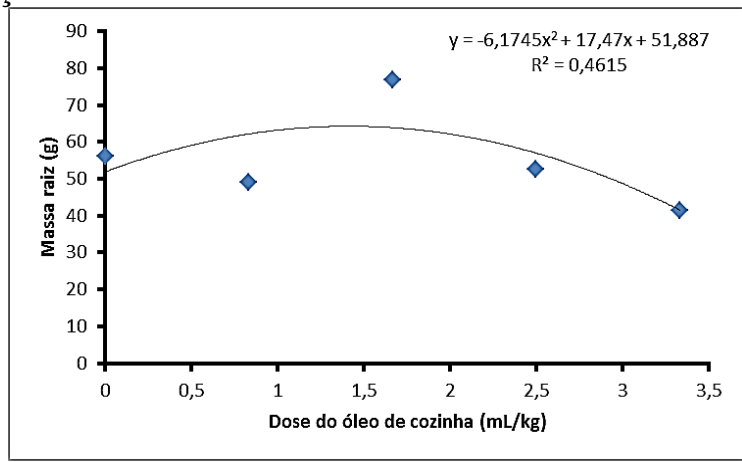

Fonte: Acervo dos Autores.

Figura 6- Relação das doses de contaminante e a massa em gramas dos caules das plantas

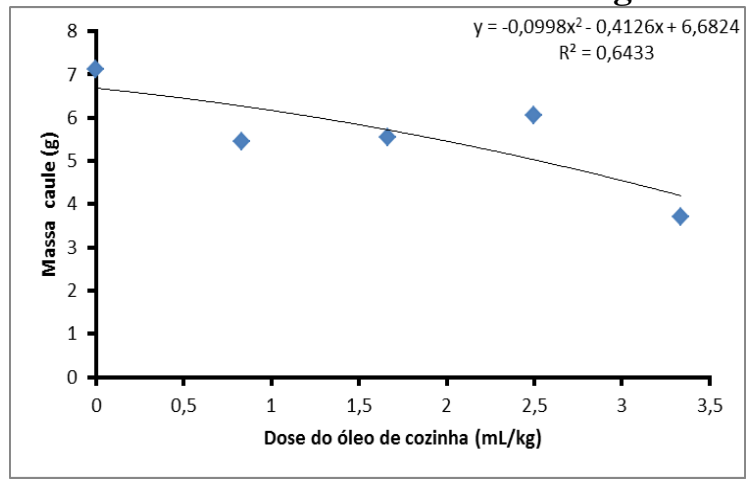

Fonte: Acervo dos Autores.

Como é notório nos gráficos a curva da relação de tratamento/dose se dá por: quanto maior a dose do contaminante mais são os efeitos visíveis nas mudas. Os tratamentos $\mathrm{T} 1, \mathrm{~T} 2, \mathrm{~T} 3$ e $\mathrm{T} 4$ se mostraram relativamente tolerantes ao contaminante apesar de apresentarem folhas arroxeadas o que indica falta de nutrientes. Isto ocorre, pois na composição química do óleo de cozinha usado há a presença de hidrocarbonetos 


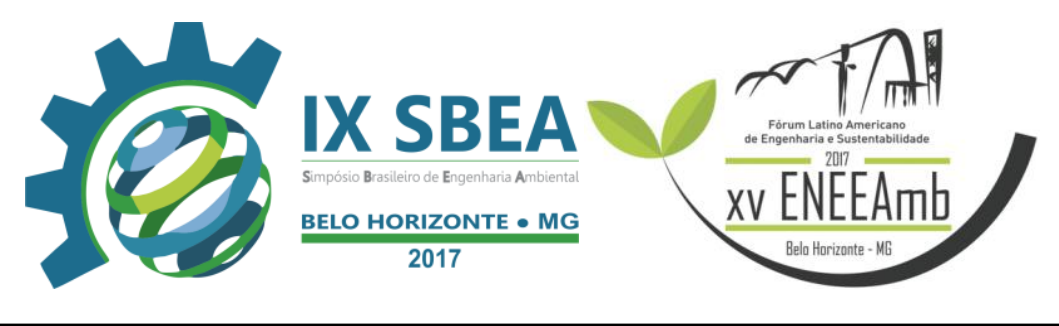

e aldeídos que impedem a atividade microbiana, essa que é responsável por ajudar a planta na absorção de nutrientes, além do fato do óleo impermeabilizar o solo, dificultando a fotossíntese da planta pela escassez da entrada de água e luz no solo.

\section{CONCLUSÃO}

A espécie estudada apresenta tolerância ao óleo de cozinha na concentração de até $2,5 \mathrm{~mL} / \mathrm{kg}$ de solo. Doses acima desse valor causam senescência na planta. Estudos mais aprofundados sobre a relação do que o óleo causa na planta internamente, assim como estudos de possível fito remediação da planta sobre o contaminante seriam interessantes para aumentar o acervo de conhecimento sobre esse gênero de cultivar.

\section{REFERÊNCIAS BIBLIOGRÁFICAS}

IVES; Anthony R.\& CARDINALE; Bradley J. Food-web interactions govern the resistance of communities after non-random extinctions.Nature 429, 174-177 (13 May 2004) / doi: 10.1038 / nature02515.

GIACHETTI; Giorgio \& SEBASTIANI; Luca.Metal accumulation in popular plant grown with industrial wastes.ChemosphereVol. 64(3): 446-454 (June 2006)/ doi: 10.1016

MAGALHÃES; Marcio, SOBRINHO; Nelson, SANTOS; Fabiana \& MAZUR; Nelson, Potencial de duas espécies de eucalipto na fitoestabilização de solo contaminado com zinco, Revista Ciência agronômica v. 42, n. 3, p. 805-812, jul-set, 2011

MAGALHÃES; Marcio, SOBRINHO; Nelson, MAZUR; Nelson, MACHADO; Hugo, \& JÚNIOR; Jesus, Desempenho de duas espécies de eucalipto em solo com elevados teores de Mn, Revista Brasileira de Engenharia Agrícola e Ambiental v.16, n.1, p.92-98, 2012

NETO, Lauro de Souza Moreira. Utilização do óleo de cozinha usado como fonte alternativa na produção de energia renovável, buscando reduzir os impactos ambientais. 2010. 